\title{
EU statistics on animal experiments for 2014
}

Directive 2010/63 on the protection of animals used for scientific purposes introduced a requirement for greater transparency on animal experiments. One of these measures was the requirement that member states submitted - and published statistics on their use of animals to the European Commission on an annual basis (Article 54(2). Furthermore, the information to be supplied increased in detail and scope from the previous requirements (see Commission Implementing Decision of 14 November 2012 establishing a common format for the submission of the information pursuant to Directive 2010/63/EU of the European Parliament and of the Council on the protection of animals used for scientific purposes (2012/707/EU)). In particular, member states now have to report the actual severity of each use of each animal as well as provide more information on the origin and species of non-human primates. They also have to report the number of genetically altered (GA) animals bred with harmful phenotypes who are not subsequently used in experiments, as these are now explicitly covered in the Directive. There is also more detailed information required on the specific tests done for regulatory purposes, with a view to enabling policy makers to track the uptake of alternatives to these tests.

2014 is the first year for which member states had to submit and publish their animal statistics according to the new format, by 10 November 2015. However, according to the Directive (Article 57(2)) these statistics do not need to be collated and published by the Commission until 10 November 2019, and every three years subsequently. There is a public interest in knowing the extent of animal experimentation in Europe, especially as the Directive is under review at the moment. We therefore submitted an Access to Documents request to the Commission to provide us with the reports as submitted to them under Article 54(2). The Commission provided us with links to the public websites of the member states that had published and confirmed that the data provided there was the same as that provided to them, see supplementary file at http:// dx.doi.org/10.14573/altex.1609291s. The 2014 report from Italy was published subsequently on 30 August 2016. By that date, all but Sweden and Portugal had made publicly available their animal statistics for 2014.

\section{Quality of the statistics}

It is not clear the extent to which the numbers in these first reports are accurate. Since this is the first year of reporting under the new format, which required significant changes to the way animals are counted (see below), it is likely that there are errors. We understand that member states are reporting difficulties with getting reporting systems in place and educating users about how to assess severity and report uses of animals. The extent of these reporting issues is likely to only become apparent over time.

However, there are also issues with providing the information at all, irrespective of quality. Only five countries provided their statistics in the full EU format; this was the UK, Denmark, Spain, Hungary and Slovakia. Austria may be complete but it is hard to tell based on their report. Sweden and Portugal have not published their 2014 statistics reports at all to date.

Those that have published have at least provided the number of experiments conducted by species. However, except for the five countries with full reports, there were tables or columns missing for all other countries. No particular tables appeared to be consistently missing; member states variably missed out reporting on severity, origin of animals, regulatory testing, legislative requirements and information on basic and applied research areas. Bulgaria and Estonia did not provide details on purpose of experiment and five countries did not report the severity of experiments (Czech Republic, Germany, Latvia, Lithuania and Slovenia). Only nine member states reported the number of GA animals bred and not used (Austria, Denmark, Finland, Germany, Italy, Netherlands, Slovakia, Spain and the UK). Only six member states listed the specific regulatory/ toxicology tests carried out (e.g., $\mathrm{LD}_{50}$, skin irritation, etc.) as required under the new format (Denmark, Hungary, Poland, Slovakia, Spain and the UK).

\section{Overall change in animal use}

The numbers of animals used in experiments appears to have risen from 2011. Even without Sweden and Portugal the total number of experiments is in excess of 12.8 million (a rise of $12 \%$ from 11.5 million in 2011) (Tab. 1). Assuming the two missing member states submit the same numbers as 2011 , then 
Tab. 1: Animals used in experiments in the European Union in 2014, according to national statistics *Flanders did not report fully.

\begin{tabular}{|c|c|c|c|c|c|c|}
\hline Country & $\begin{array}{l}2014 \\
\text { (procedures) }\end{array}$ & $\begin{array}{l}2011 \\
\text { (animals) }\end{array}$ & $\%$ change & $\begin{array}{l}\text { No. GA animals } \\
\text { bred reported }\end{array}$ & $\begin{array}{l}\text { No. non-human } \\
\text { primates used }\end{array}$ & $\begin{array}{l}\% \text { severe } \\
\text { suffering }\end{array}$ \\
\hline Austria & 209,183 & 191,288 & +9 & Yes & 0 & 10 \\
\hline Belgium & 664,471 & 665,079 & 0 & No & 46 & *15 \\
\hline Bulgaria & 12,695 & 17,259 & -26 & No & 0 & 27 \\
\hline Croatia & 25,998 & Not in EU & $\mathrm{n} / \mathrm{a}$ & No & 0 & No data \\
\hline Cyprus & 640 & 1,328 & -52 & No & 0 & 0 \\
\hline Czech Republic & 231,397 & 354,196 & -35 & No & 63 & No data \\
\hline Denmark & 202,609 & 282,840 & -28 & Yes & 0 & 1 \\
\hline Estonia & 6,164 & 41,035 & -85 & No & 0 & 2 \\
\hline Finland & 145,542 & 136,043 & +7 & Yes & 0 & 5 \\
\hline France & $1,769,618$ & $2,220,152$ & -20 & No & 1,103 & 9 \\
\hline Germany & $2,798,463$ & $2,073,702$ & +35 & Yes & 2,842 & No data \\
\hline Greece & 42,243 & 28,001 & +51 & No & 0 & 7 \\
\hline Hungary & 200,965 & 276,179 & -27 & No & 3 & 7 \\
\hline Ireland & 226,684 & 264,990 & -15 & No & 0 & 40 \\
\hline Italy & 698,059 & 781,815 & -11 & Yes & 858 & 3 \\
\hline Latvia & 13,730 & 10,329 & +33 & No & 0 & No data \\
\hline Lithuania & 3,450 & 4,067 & -15 & No & 0 & No data \\
\hline Luxembourg & 2,296 & 502 & +357 & No & 0 & 0 \\
\hline Malta & 0 & 10 & -100 & $\mathrm{n} / \mathrm{a}$ & $\mathrm{n} / \mathrm{a}$ & $\mathrm{n} / \mathrm{a}$ \\
\hline The Netherlands & 563,769 & 514,617 & +10 & Yes & 238 & 2 \\
\hline Poland & 233,323 & 282,160 & -17 & No & 10 & No data \\
\hline Portugal & No data & 46,556 & No data & No data & No data & No data \\
\hline Romania & 19,735 & 60,156 & $-67 \%$ & No & 0 & 0 \\
\hline Slovakia & 16,812 & 15,717 & +7 & Yes & 0 & 1 \\
\hline Slovenia & 11,794 & 11,874 & -1 & No & 0 & No data \\
\hline Spain & 821,570 & 900,127 & -9 & Yes & 489 & 8 \\
\hline Sweden & No data & 271,041 & No data & No data & No data & No data \\
\hline UK & $3,887,296$ & $2,050,458$ & +90 & Yes & 3,246 & 4 \\
\hline Total & $12,808,506$ & $11,481,521$ & $+12 \%$ & & 8,898 & \\
\hline
\end{tabular}

the projected total is actually 13.1 million, an increase of $14 \%$ on 2011.

There are at least two reporting factors that are likely to explain the total number. Firstly, the numbers being reported are animals that have completed experiments. It is no longer the numbers of animals per se. Some animals will be used more than once so the overall total figure is likely to be higher than if just counting animals. For some types of experiments such as blood sampling or pyrogenicity tests, several experiments can be conducted on the same animal within a year. The numbers are therefore not directly comparable with previous years for this reason. However, based on experience with the UK, who have reported both animals and experiments since 1987, the total number of animals is still usually only slightly less than the total number of experiments, as most animals are killed at the end of a single experiment.

Secondly, GA animals bred and not used are now supposed to be counted. This typically accounts for $30-50 \%$ of animals used 
in the UK as they have counted these animals for years. However, the UK counts all GA animals, not just those considered to have harmful phenotypes, since it is often difficult to tell. So, whilst we might not have expected the numbers of animals reported across Europe to have doubled, we had expected a significant rise due to the reporting of GA animals.

Out of the largest users of animals in experiments (using more than 1 million animals), the UK increased by $90 \%$, Germany increased by $35 \%$ but France reported 20\% fewer experiments than in 2011 (actually 2010), see Table 1 . The UK is now the biggest reported user of animals in the EU with 3.9 million experiments per year. Germany is the second highest user with 2.8 million and France third with 1.8 million animals.

Out of those using less than 1 million animals but more than 100,000 animals; Denmark, Czech Republic, Spain, Hungary, Ireland and Poland reported a decrease while Austria, Finland and The Netherlands reported an increase. Belgium's use stayed almost exactly the same. The overall increase is therefore explained mostly by the significant increase in numbers from the UK and Germany.

There remain a number of countries (twelve in 2014) that report relatively limited animal use of less than 100,000 experiments. Fluctuations in their numbers can give rise to large percentage changes from 2011 but have little influence on the overall number for the EU. Malta reported using no animals in 2014.

\section{Severity of experiments}

For the first time, member states now have to report the actual severity of the procedures for each and every animal, as considered by the researcher doing the assessment. The categories are non-recovery (procedure done entirely under general anaesthesia and the animal does not regain consciousness), mild, moderate and severe. Five member states did not provide this information. Using severe suffering as an example, see Table 1, there is wide variation in the reports of suffering. Most countries report severe suffering in less than $10 \%$ of the animals. However, Austria (10\%) Belgium (15\%), Bulgaria $(27 \%)$ and Ireland $(40 \%)$ reported higher levels of suffering.

\section{Trends in specific species}

8.2 million mice were reported to be used in experiments, 1.8 million fish and 1.4 million rats. 155,502 guinea pigs, 21,580 hamsters and 54,207 other rodents were used in experiments. 318,259 rabbits, 3,851 cats and 22,967 dogs were used in experiments. There were 11,250 experiments on equines, 72,749 on pigs, 2,655 on goats, 60,209 on sheep and 34,256 on cattle. There were 599,185 experiments on birds, 3,336 on reptiles and 59,814 on amphibians. Spain reported the vast majority of the 4,879 experiments on cephalopods.

8,898 experiments were on non-human primates, of which 7,693 involved cynomolgous or rhesus macaques (Tab. 1). Compared to 2011 numbers the use of old world monkeys increased by $49 \%, 8 \%$ for new world monkeys. Baboons were used in France (149 experiments), Spain (32 experiments) and Germany ( 2 experiments). Ten member states reported the use of primates in 2014. Every primate-using country reported a significant increase in the number of primate experiments conducted in 2014 except for France, who reported a 39\% decrease.

Out of the 10 countries that used primates in 2014, only six countries provided detailed information on the wildcaught status of the animals. Germany, Belgium, the Czech Republic and Poland did not provide any data and France and the Netherlands reported this by number of experiments not "animals used for the first time". Based on these figures, approximately $50 \%$ were from self-sustaining colonies, $31 \%$ of primates were F2 generation or greater, $12 \%$ were F1 and 1 primate was F0 (wild caught). $7 \%$ (311 primates in the French statistics) were not specified.

There were notable $( \pm 20 \%)$ increases in the use of dogs $(28 \%)$, equines $(68 \%)$, sheep $(108 \%)$, old world monkeys (49\%), prosimians (157\%), amphibians (102\%) and fish (28\%). The change in reporting could explain some of these rises; dogs, horses and primates are commonly re-used for some regulatory testing purposes.

\section{Trends in general purposes}

There was quite a lot of variation in the distribution of the broad purposes of procedures between the member states (see Fig. S1 in http://dx.doi.org/10.14573/altex.1609291s). Users of fewer

Tab. 2: No. skin irritation, eye irritation and skin sensitisation tests on animals in 2011 and 2014 in six reporting member states

\begin{tabular}{|l|c|c|c|c|c|c|c|c|}
\cline { 2 - 8 } \multicolumn{1}{c|}{} & Year & Denmark & Spain & UK & Poland & Slovakia & Hungary & Total \\
\hline \multirow{2}{*}{ Skin irritation } & 2014 & 24 & 25 & 659 & 202 & 0 & 60 & 970 \\
\cline { 2 - 9 } & 2011 & 268 & 267 & 1,101 & 203 & 0 & 377 \\
\hline \multirow{2}{*}{ Eye irritation } & 2014 & 3 & 6 & 435 & 62 & 3 & 31 \\
\cline { 2 - 9 } & 2011 & 0 & 84 & 692 & 39 & 12 & 328 \\
\hline \multirow{2}{*}{ Skin sensitisation } & 2014 & 192 & 610 & 6,047 & 1,028 & 0 & 7,150 \\
\cline { 2 - 9 } & 2011 & 134 & 620 & 1,354 & 570 & 3 & 4,877 \\
\hline
\end{tabular}


animals were more likely to report significantly higher numbers of basic research experiments, such as Croatia, Cyprus, Finland, Greece, Lithuania, Luxembourg and Slovakia.

France, Ireland, Latvia and Slovenia reported that over 50\% of experiments were for regulatory purposes. The Czech Republic and Romania reported the highest proportion of education and training use ( $7 \%$ and $10 \%$, respectively).

\section{Trends in regulatory tests with alternatives}

Only six member states completed the regulatory testing by test type tables (see Tab. 2) and only a handful of tests are directly comparable with the 2011 statistics format (bearing in mind the animals versus experiments difference). In the reporting countries there were 970 skin irritation tests, a 56\% decrease on 2011. Similarly, there was a 53\% decrease in eye irritation tests in these countries, from 1,150 animals to 540 tests. However, there was an $11 \%$ increase in skin sensitisation tests from 2011 to 7,877 tests.

\section{Conclusion}

Most member states have not published (or apparently even sent to the Commission) the statistics in the full EU format as required under Commission Implementing Decision 2012/707/ EU. The majority have published only brief reports for 2014, covering the number of animals by species, sometimes supplemented with information on purpose or severity by species. Data on the types of regulatory tests for most member states is missing. Only five appear to have provided complete data sets.

Furthermore, based on a brief analysis of the data available it appears that member states may be interpreting differently the requirements to report the use of GA animals and/or animals considered to have suffered below the threshold. This suspicion is based on the large variation in changes in number of experiments/animals between the member states from 2011. The UK appears to have dramatically increased its animal use (based on previous UK reports there has been a real increase but not to this extent), whereas countries that would be expected to have at least increased their total, based on the change in reporting requirements, such as France, Denmark, Czech Republic and Hungary, appear to have significantly decreased their use.

The annual statistics are an important source of information on the uses of animals in each member state and if collated can give a picture of use across the EU. The improvement to the reporting outlined in Article 54 (2) and provided in the Commission Implementing Decision 2012/707/EU was intended to increase the transparency of animal testing required under Recital 4 of the Directive. The reporting is meant to include information on the severity of experiments, the areas of basic and applied research and quite specific information on the types of tests done for regulatory purposes. Information in these areas was required particularly to help policymakers monitor the uptake of alternatives and to help prioritise investment in the 3Rs. It is unfortunate that the first reports are inadequate and it is important that both member states and the Commission are tasked with urgently improving their quality and completeness.

Katy Taylor and Laura Rego

Cruelty Free International

Charitable trust, London, UK

katy.taylor@crueltyfreeinternational.org 